\title{
TICK SALIVA TOXINS, HOST IMMUNE RESPONSES AND ITS BIOLOGICAL EFFECTS
}

\author{
NIDHI YADAV, RAVI KANT UPADHYAY \\ Department of Zoology, Deen Dayal Upadhyaya Gorakhpur University, Gorakhpur \\ Email: rkupadhya@yahoo.com
}

Received: 15 Mar 2021, Revised and Accepted: 29 Jun 2021

\begin{abstract}
Ticks are the most important ancient group of obligate blood-sucking ectoparasites of terrestrial vertebrates mainly of livestock. These small-sized animals are found in tropical and sub-tropical regions of the world. These act as vectors and transmit a wide range of protozoa, bacteria and viruses tickborne diseases. These attach to host skin for blood-sucking and transmit disease pathogens through saliva. Ticks withdraw large volumes of blood from livestock and make them anemic and do significant weight loss. Ticks cause severe economic losses in livestock directly through blood-feeding and indirectly by transmitting protozoan, rickettsial and viral diseases This article highlights toxins/proteins secreted in tick saliva, and its important biological effects like anti-inflammatory, immunosuppressant peptide, and immunomodulatory and anti-chemokine activities. The present article clears host-pathogen interactions and invasion of a host by ticks, biological effects of tick saliva toxins and its host immune responses. These toxins could be used as immunoreactive proteins as a prerequisite for the development of specific and sensitive immunoassays for the determination of tick-borne illness. The authors suggest important management strategies for successful control of cattle, bird and canine ticks. This article also suggests tick control
\end{abstract} methods such as physical, chemical, hormonal and including prophylactic use of antibody and vaccine immune therapy.

Keywords: Ticks, Blood sucking ectoparasites, Disease transmission, Saliva toxins, Biological effects, Tick control and management

(C) 2021 The Authors. Published by Innovare Academic Sciences Pvt Ltd. This is an open access article under the CC BY license (https://creativecommons.org/licenses/by/4.0/) DOI: https://dx.doi.org/10.22159/ijpps.2021v13i8.41444. Journal homepage: https://innovareacademics.in/journals/index.php/ijpps.

\section{INTRODUCTION}

Ixodid ticks are arachnids, having a body length of 3 to $5 \mathrm{~mm}$, belong to superorder Parasitiformes. Along with mites, they constitute the subclass Acari. Ticks are obligate blood-sucking ectoparasites of terrestrial vertebrates mainly mammals, birds, reptiles and amphibians. These also cause severe consequences to human and animal health worldwide. There are a number of arthropods of medical importance, including vespids, ticks, mosquitoes, flies, and fleas mites and ticks. These small-sized animals spread diseases working as vectors. These produce deadly toxins and cause lethal allergic reactions. They are major vectors of arthropod-borne pathogens in both tropical and sub-tropical and even in temperate countries [1-3]. Ticks transmit a number of different types of pathogens (viruses, rickettsiae, and spirochete), bacteria, fungi, protozoa, and filarial nematodes. These were evolved over millions of years [4]. They are exclusively hematophagous in all feeding stages of their life cycle and have considerable medical and veterinary importance [5] (table 1).

Ticks are blood feeders that can attach to the host skin for days to weeks using their saliva to counteract the host defenses. Ticks cause damage directly by affecting the site of infestation, or indirectly as vectors of a wide range of protozoa, bacteria and viruses tick-borne diseases ultimately lead to lower productivity of livestock populations. Hard ticks are characterized by hard shields or scutum [6-9]. Hard ticks possess a beak-like structure at the front containing the mouthparts; whereas soft ticks have their mouthparts on the underside of their bodies. Adults have ovoid or pear-shaped bodies, which become engorged with blood when they feed, and eight legs. Ticks possesses hard shield on their dorsal surfaces. There is another big family Argasidae of ticks, which represents' soft ticks' and lack hard shield. Ixodidae is the family of hard ticks or scale ticks one of the two big families of ticks. It consists of over 700 species $[10,11]$. Currently, 904 valid tick species have been listed throughout the world [12-17] (table 1).

Ticks evolved by the Cretaceous period, the most common form of fossilization being amber immersion. Ticks are widely distributed around the world, especially in warm, humid climates. Hyalomma anatolicum and Haemaphysalis bispinosa was observed inside the cattle sheds. ixodid ticks in Maharashtra, India, was undertaken during 1976 to 1978 [18]. Haemaphysalis bispinosa and R (B.) microplus are prevalent throughout India, while $H$. spinigera is restricted to southern states, central zones, Orissa and Meghalaya [18]. A total of 23 species of ticks were reported in domestic and wild animals from the different parts of Kerala State $[19,20]$. Ticks salivary glands secrete toxins and passed into the blood through feeding, make livestock anemic and cause great economic losses to the livestock worldwide [21]. Ticks also secrete various anti-coagulatory, anti-vasoconstrictory, antiinflammatory, and anti-platelet aggregation factors in their saliva at the bite site during feeding to evade human and other animal hosts [22]. Tick saliva is used as an invading liquid that imposes multiple severities in host and do impairment of physiological health [22]. Ticks are responsible for the spread of diseases like Anaplasmosis, Babesiosis and Ehrlichiosis (table 1) (fig. 1)

\section{Source of information}

For writing this comprehensive research review on hymenopteran toxins/allergens, various databases were searched. For the collection of relevant information, specific terms such as medical subject headings (MeSH) and key text words, such as "venom allergens", "biological and pharmaceutical effects", therapeutic uses" published till 2020 were used in MEDLINE. Most specially for retrieving all articles pertaining to the use of VIT for insect venom allergy, electronic bibliographic databases was searched and abstracts of published studies with relevant information on the venom toxins/allergens were collected. Furthermore, additional references were included through searching the references cited by the studies done on the present topic. Relevant terms were used individually and in combination to ensure an extensive literature search. For updating the information about a subject and incorporation of recent knowledge, relevant research articles, books, conferences proceedings and public health organization survey reports were selected and collated based on the broader objective of the review. This was achieved by searching databases, including SCOPUS, Web of Science, and EMBASE, Pubmed, PMC, Publon, Swiss rot, Google searches" From this common methodology, discoveries and findings were identified and summarized in this final review.

\section{Tick habitat}

Ticks usually live in sandy soil, hardwood trees, and rivers, with an overt story of trees or at least shrubs. These also live in crevices near 
animal dens or nests, found inside human dwellings where dwell in dark and very silently attacks roosting birds. These are slow-moving tiny creatures incapable of flying or jumping. These completely depend on blood meals from hosts and have successfully developed counteractive means against their hosts' immune and homeostatic mechanisms. They move by sensing carbon dioxide released in the breath of their hosts [23]. They deposit their eggs in dark places, mainly in crevices in the spring season, where new larvae can emerge, fall and crawl into low-lying vegetation. The most preferred place for ticks is the interface where a lawn meets to a patched grassy ground. Ticks live on the side lawn's edge where they crawl swiftly are a tick migration zone. More than $82 \%$ of tick nymphs reside inside lawns [24]. Ixodid ticks are also found in the vegetation grounds where antelopes and other herbivores come to forage in closed enclosures; where ticks show free-living intensively in large numbers. Ticks found in open grasslands to urban woody material, carpets, doormats and cloth seats. They also found in Antarctica, where they found stuck on penguins and feed upon their blood [25]. Ticks found in high-density sticks over the ears, groin, tail and anal region of mammals. Ticks can survive temperatures in the $20-29^{\circ} \mathrm{F}$ temperature for at least two weeks. They can withstand temperatures just above $0^{\circ} \mathrm{F}\left(-18^{\circ} \mathrm{C}\right)$ for more than two hours.

\section{Tick life cycle}

Ticks have four stages in their life cycle, namely egg, larva, nymph, and adult. Ixodid ticks have three hosts, taking at least a year to complete their life cycle. Argasid ticks have up to seven nymphal stages (instars), each one requiring a blood meal. Early-stage or hatching stage early larva possesses six legs, acquiring the other two after a blood meal and molting into the nymph stage [26]. Both nymphal and adult stages, of ticks possess eight legs, each of which has seven segments and is tipped with a pair of claws. Their soft tiny legs bear sensory or tactile hairs which help them to find a suitable site on host skin [27]. Ticks attach to a host bite. They remain to engorge deep into the skin and regularly suck blood this process may take days or weeks. All life stages of ixodid ticks have a destructive pool-feeding style in which they create a pool-feeding site by lacerating host tissue and secreting a variety of biologically active compounds. These compounds make the ticks to evade host responses, enabling the uptake of a blood meal [28].

Ticks detect animal host by breathing carbon dioxide and body odors. They also sense through body heat, moisture, and vibrations [29]. Upon locating a suitable feeding spot, the tick grasps the host's skin and cuts into the surface [30]. They extract blood by cutting a hole in the host's epidermis, into which insert their hypostome and keep the blood from clotting by excreting an anticoagulant or platelet aggregation inhibitor [31-32]. Ticks are also widely distributed among host Texas, which include marsupial and placental mammals, birds, reptiles (snakes, iguanas, and lizards), and amphibians [33]. Because of their habit of ingesting blood, ticks are vectors of many diseases that affect humans and other animals. Migrating birds carry ticks with them on their journeys. Ticks of domestic animals cause considerable harm to livestock by transmission of many species of pathogens, as well as causing anemia and damaging wool and hides [34] (table 1)(fig. 1).

\section{One-host ticks}

Both ixodid and argasid ticks have four lifecycle stages: egg, larva, nymph, and adult [35]. Female ticks lay eggs that hatch into larvae, immediately after development they need a host for nourishment. Fed larvae molt into unfed nymphs that remain on the host. After engorging on the host's blood, the nymphs molt into sexually mature adults that remain on the host in order to feed and mate. Once a female is both fed and ready to lay eggs, only then does she drop off the host in search of a suitable area to deposit her eggs. Winter tick Dermacentor albipictus and the cattle tick Boophilus microplus are examples of one-host ticks [36]. Experimental transmission of bovine anaplasmosis (caused by Anaplasma marginale) by means of Dermacentor variabilis and $D$. anderson (Ixodidae) collected in western Canada [37]. Epidemiology and ecological significance of infection is important to quantify the clinical and socio-economic impact of the disease cause [38] (table 1).

\section{Two-host ticks}

Newly hatched larvae attach to a host in order to obtain a blood meal. They remain on the host after developing into nymphs. After emerging from their shed larval skins, the nymphs reattach to the host and feed. Once engorged, they drop off the host and find a safe area in the natural environment in which to molt into adults. Both male and female adults seek out a host on which to attach, which may be the same body that served as host during their early development. Once attached, they feed and mate. Females ready to lay eggs drop from the host to oviposit in the environment. Ticks that complete their life cycle in this manner are called two-host ticks, like Hyalomma anatolicum excavatum [39] (table 1).

\section{Three-host ticks}

Most ixodid ticks require three hosts, and their life cycles take at least a year to complete. Thousands of eggs are laid on the ground by an adult female tick. When the larvae emerge, they attach and feed primarily on small mammals and birds. After feeding, they detach from their hosts and molt to nymphs on the ground, which then attach and feed on larger hosts before dropping off yet again in order to molt into adults. Adults seek out a third host on which to feed and mate. Female adults engorge on blood and prepare to drop off to lay her eggs on the ground, while males feed very little and remain on the host in order to continue mating with other females [39] (table 1).

\section{Transmission of diseases}

Ticks are the most important ectoparasites of livestock in tropical and sub-tropical areas. These are responsible for severe economic losses both through the direct effects of blood-sucking and indirectly as vectors of pathogens and toxins. Ticks rely on blood meal for which they obtain from vertebrate hosts at each developmental stage for completion of their life cycle. Blood feeding severely impacts animal health by causing damage to hides, secondary infections, immune reactions and diseases caused by the transmission of pathogens. Feeding of a large amount of ticks, causes a reduction in live weight gain and anemia among domestic animals, while tick bites also reduce the quality of hides. Black-legged tick Ixodes pacificus (Acari: Ixodidae) spread the pathogen, Ehrlichiacasis. Ixodes scapularis (L.) is the most abundant tick species encountered by humans and the primary vector of $B$. burgdorferi found in East and Upper Midwestern regions of North America. Ticks and tick-borne diseases (TBDs) undermine cattle fitness and productivity worldwide. Ticks also feed on birds, domestic and wild animals. Birds, particularly passerines, are parasitized by Ixodid ticks (table 2). Ticks infest cattle in large numbers. Ticks and tick-borne diseases are a major impediment to livestock production worldwide. Ticks are also spread through cattle trade and transnational transhumance movements. These create risks for the spread of ticks and tick-borne diseases and threaten cattle production. Ticks spread tick-borne pathogens, like Borrelia spp., Babesia spp., Anaplasma, Rickettsia/Coxiella, and tick-borne encephalitis virus. Theileria parva is a protozoan parasite, which causes the tick-transmitted disease East Coast fever in cattle. Theileria are tick-transmitted protozoans causing often fatal diseases in ruminants. However, the major losses caused by ticks are due to the ability to transmit protozoan, rickettsial and viral diseases of livestock, which are of great economic importance worldwide [40]. Ticks and tick-borne diseases (TBDs) affect the productivity of bovines in tropical and subtropical regions of the world, leading to a significant adverse impact on the livelihoods of resource-poor farming communities [40] (table 2).

Ticks transmit a wide range of viral, bacterial and protozoan pathogens; many of them establish persistent infections of lifelong duration in the vector tick. In some cases, tick-borne diseases are transmitted transovarially to the next generatiorboffiek anaplasmosis and ehrlichiosis are clinically important emerging zoonoses ticks belonging to three genera (Rhipicephalus, Hyalomma, Haemaphysalis). Tick-borne relapsing fever in North America is primarily caused by the spirochete Borrelia hermsii. Babesial vector tick defensin against Babesia sp. Parasites Wild canines and whitetailed deer found infected with Borreliae in ticks, and transmit tick- 
borne viruses (TBV) (table 2). Most of them are RNA viruses of humans and animals. Tick-borne diseases are also spread by birds which feed on Borrelia burgdorferi Sensu Lato-infected black-legged mites and nematodes.

More especially ticks are indirectly assisting in controlling animal populations and preventing overgrazing by spreading diseases in grazers [42]. Ticks are also spread by movements of people, their pets, and livestock. All outdoor activities like wilderness hikes, more people and their dogs may find themselves exposed to ticks and tickborne diseases [43]. Ixodid ticks are well known for spreading transmitted tick-borne pathogens while being attached to their hosts for almost 1-2 w to obtain blood meals. Four members of the Ixodes ricinus species complex, Ixodes pacificus, Ixodes persulcatus, Ixodes ricinus and Ixodes scapularis, have, between them, a worldwide distribution within the northern hemisphere (table 2).

Ixodes ricinus is a major pest of sheep, cattle, deer, dogs and humans. Few medically important ixodid ticks include Amblyomma spp, Anomalohimalaya spp, Bothrio crotons spp, Cosmiomma sp, Dermacentor spp, Haemaphysalis spp, Hyalomma spp, Ixodes spp, Margaropus spp, Nosomma sp, Rhipicentor spp, and Rhipicephalus spp. Ixodes ricinus a free living tick has been intensively studied [45]. The nymph of the western black-legged tick (Ixodes pacificus) is an important bridging vector of the Lyme disease spirochete (Borrelia burgdorferi) to humans in the far western United States [46]. These show horizontal and vertical movements of host-seeking Ixodes pacificus (Acriixodidae) nymphs in a hardwood forest. Two main species of ticks are Ixodes hexagons or brown Ixodid ticks live on the bodies of domestic and wild animals and on vegetation (table 2).

\section{Tick-borne diseases}

Ticks are implicated in the transmission of a number of infectious diseases caused by various groups of pathogens such as bacteria, viruses, and protozoa. Ticks spread infectious diseases such as Lyme borreliosis, ehrlichiosis, anaplasmosis, babesiosis. In last four decades due to the movement of human population and domestic and wild animals, trade and traffic ticks are arriving into new endemic regions of the world. Exposure of tick-borne pathogens is increasing in geographic ranges that are resulting in heavy morbidity and mortality. Ticks induce paralysis, as an arachnid that is more dangerous than envenomation [47]. Hyalomma and Ixodes ticks infest migratory birds in the European Mediterranean Islands: Capri and Antikythira. These are responsible for spreading of spotted fever caused by Rickettsia species [48] Borrelia burgdorferi infection is common in horses while Borrelia miyamotoi in humans. Living in Lyme endemic areas and the geographic range of exposure is increasing. The $C$. burnetii strains belong to the group of agents causing acute forms of $Q$ fever [49] (table 2) (fig. 1).

Anaplasmosis is an emerging zoonotic disease with a natural enzootic cycle. This diseases is spread by Ixodes ricinus is the principal vector of Anaplasma phagocytophilum. Theileria annulata is a tick-transmitted protozoan parasite of cattle, which transforms cells of macrophage (Mphi) or B cell lineage [50]. Theileria sporozoites immortalize and transform host cells of haematopoietic origin [50]. Ticks Ixodes scapularis and Ixodes ricinus are infected by Borrelia burgdorferis and S. Ehrlichia ruminantium.

Ticks are efficient vectors of arboviruses, although less than $10 \%$ of tick species are known to be virus vectors. Ticks transmit viruses of flaviviridae virus family mainly Kyasanur Forest Disease Virus (KFDV). Anaplasma phagocytophilum causes human granulocytic anaplasmosis, one of the most common tick-borne diseases in North America. This unusual obligate intracellular pathogen selectively persists within polymorphonuclear leukocytes. Tick also transmits Tofla virus; a Nairovirus of the Crimean-Congo hemorrhagic fever group found in Japanese ticks (table 2).

Ticks spread infection of bacterial genus Rickettsia mainly typhus, rickettsialpox, boutonneuse fever, African tick bite fever, Rocky Mountain spotted fever, Flinders Island spotted fever, and Australian tick typhus [51]. Ticks also transmit pathogens of other diseases include Lyme disease and Q fever [52], Colorado tick fever, Crimean Congo hemorrhagic fever, tularemia, tick-borne relapsing fever, babesiosis, ehrlichiosis, Bourbon virus, and tick-borne meningoencephalitis, as well as bovine anaplasmosis and Heartland virus [53]. The tick Ixodes holocyclus cause envenomation in the horse and induce hemorrhagic fever [54] (table 2) (fig. 1).

The ixodid genus includes important disease vectors of animals and humans. Ticks transmit disease organisms such as the bacterium Borrelia burgdorferi, which causes Lyme disease, and tick-borne encephalitis (TBE) virus through saliva. In addition the protozoan Babesia and the bacterium Anaplasma cause diseases in livestock. Rocky Mountain spotted fever, a systemic tick-borne illness is caused by an obligate intracellular bacterium Rickettsia rickettsii. This is associated with widespread infection of the vascular endothelium [55]. Ticks carry zoonotic disease viruses from animals to humans and generate severe health-related consequences to man, livestock, dogs, sheep, cows, buffaloes, antelopes, horses, ferrets, and cats [56] (table 2) (fig. 1).

\section{Tick-borne babesiosis}

Tick-borne babesiosis is an emerging zoonosis. This is a wellrecognized malaria-like disease prevail worldwide [57]. Babesiosis is an important tropical tick-borne haemoprotozoan disease occurs in dogs. This is a potentially life-threatening illness caused by intra erythrocytic protozoan parasites of the genus Babesia. This pathogen is transmitted most commonly by Ixodes ticks, it also rarely occurs through blood transfusion or congenitally. This is clinically manifested by anorexia, dehydration, temperature, dullness/depression, diarrhea/constipation, pale mucosa, hepatomegaly, vomiting/nausea, splenomegaly, distended abdomen/ascites, yellow coloured urine, emaciation/weight loss, and ocular discharge [58]. Antibiotics such as atovaquone plus azithromycin or clindamycin and quinine are used to treat this disease. The disease causes heavy mortality in high-risk populations in spite of antibiotic therapy [59] (table 2) (fig. 1).

\section{Tick-borne paralysis}

Tick-induced paralysis is the most widespread and dominant form of tick toxicoses is caused by Amblyomma aculatum on the Mexican Pacific Coast [60]. Australian paralysis is caused by tick Ixodes holocyclus [61]. This tick species secrete toxins that produce positive inotropic responses in rat left ventricular papillary muscles and positive contractile responses in rat thoracic aortic rings [61]. Tickborne relapsing fever is evoked by spirochetes which are bloodborne pathogens transmitted through the saliva of soft ticks [62]. Destruxin A secreted by Rhipicephalus (Boophilus) microplus ticks (Acari: Ixodidae) causes tetanic paralysis [63] (table 2) (fig. 1).

\section{Tick-borne encephalitis}

Ticks are important vectors for the transmission of pathogens including viruses. Tick-borne encephalitis virus (TBEV) and Omsk hemorrhagic fever virus (OHFV) are highly pathogenic ticked-borne flaviviruses. These are leading causes of encephalitis that is an emerging disease, spreading in many regions in Eurasia in dogs. Dogs become readily infected with the TBE virus, but they are accidental hosts not capable to further spread the virus. TBEV causes neurological disease in humans, while OHFV causes a disease typically identified with hemorrhagic fever [64]. Tick secrete a highly paralytic and lethal venom cocktail of proteinaceous molecules contain neurotoxins HT-1, present in the saliva ticks despite several species possessing saliva of the Australian paralysis tick [65]. Tick bites causes anaphylaxis in patients allergic to bee venom. Ticks are also responsible for the transmission of several animal and human pathogens, including the causal agents of Lyme borreliosis, tick-borne encephalitis, human granulocytic anaplasmosis and human babesiosis [66]. Powassan virus is a neurovirulent flavivirus that causes meningoencephalitis in North America and display severe neurological symptoms [67] (table 2).

Tick also harbors endogenous viruses and modulation of tick-borne pathogen growth. The viruses carried by tick's also known as tickborne viruses (TBVs), contain a large group of viruses with diverse genetic properties and are concluded in two orders, nine families, and at least 12 genera. Tick-borne encephalitis virus (TBEV) is a major arbovirus that causes thousands of cases of severe neurological illness in humans annually [68]. The salivary gland 
secretions in the hematophagous parasites, blood sucking arthropods such as ticks have a greater role to counteract their vertebrate host's homeostasis, inflammation, and immunity [69]. Tick saliva contains microbiome communities of microorganisms, including viruses, bacteria and eukaryotes [70]. The obligate intracellular bacterium Ehrlichia ruminantium (ER) causes hot-water, a fatal tick-borne disease in livestock [71]. Ehrlichia chaffeensis is a tick-transmitted obligate intracellular pathogenic bacterium, which causes human monocytic ehrlichiosis and putative host cell targets during infection [72] (table 2) (fig. 1).

\section{Lumpy skin disease}

The Lyme disease-causing organism, Borrelia burgdorferi is transmitted into the mammalian host by an infected-tick bite Lumpy skin disease (LSD). This causes economic losses to the cattle industry in Africa and the near and Middle East. Ixodid ticks include the genera Rhipicephalus (i.e., brown dog tick), Dermacentor (i.e., American dog tick, Rocky Mountain wood tick, Pacific or West Coast tick), Ixodes (i.e., shoulder tick of North America, deer tick, British dog tick [Europe], Amblyomma (black-legged tick, Lone Star tick), and Haemophysalis yellow dog ticks [Africa and Asia] and cause lumpy skin disease (table 2) (fig. 1).

\section{Lyme disease}

Ixodid ticks are notorious bloodsucking ectoparasites and are completely dependent on blood meals from the hosts. Lyme borreliosis is caused by Ixodes-tick transmitted spirochete Borrelia burgdorferi consulate bacteria transmitted to humans by the bite of hard ticks, Lyme disease is the commonest worldwide [75]. This disease is a potential health threat to the Canines mainly dogs, and lives stocks. It manifests with arthritis-induced lameness, anorexia, fever, lethargy, lymphadenopathy and, in some cases, fatal glomerulonephritis The Lyme disease, parasite Borrelia burgdorferi, possesses a number of outer membrane proteins that are differentially regulated during its life cycle. During natural infection with the agent of Lyme disease, Borrelia burgdorferi, spirochetes are delivered with vector saliva, which contains anti-inflammatory and antihemostatic activities [74] (table 2) (fig. 1). The vaccine could be an efficient approach to decrease Lyme disease incidence.

\section{Rickettsioses}

Rickettsioses have epidemiological importance that includes pathogens, vectors, and hosts is caused by dog tick Rhipicephalus sanguineus and the camel ticks Hyalomma dromedarii. These are important vectors and reservoirs of Rickettsiae vectors of Rickettsioses (Acari: Ixodidae) infected male ticks do sexual transmission of spotted fever group rickettsiae. Rickettsiae have been detected in spermatogonia, spermatocytes, and maturing spermatids [75] (fig. 1).

\section{Bacterial diseases}

Common marmosets are susceptible to a number of bacterial infections, which may be exotic, causing sporadic but occasionally severe disease. They secrete potential toxic molecules in the blood remains Ixodid ticks, in combination with bacterial transmission; induce a robust inflammatory response at the blood-feeding site. Hard Tick Amblyomma variegatum causes theileriosis is a blood piroplasmic disease that adversely affects the livestock especially in tropical and sub-tropical countries. It is caused by haemoprotozoan found in hard ticks (table 2).

Tick-borne pathogens (TBPs), especially Anaplasma phagocytophilum, cause disease in grazing livestock. Human seventrans-membrane (7TM) G protein-coupled chemokine receptor is a large family of leukocyte chemo-attractant receptors. It regulates immune system development and function, in large part by mediating leukocyte trafficking during infection or wound healing. Borrelia species generate the production of four inflammatory cytokines. Tick-host interactions during feeding are complex, with host immune responses influenced by biological differences in tick feeding and individual differences within and between host species. One of the first encounters for spirochetes entering the vertebrate host skin occurs with local antigen-presenting cells. While to tick- associated Borrelia sp. evoke pathogens cytokine responses in THP1-derivedmacrophages after exposure to selected borreliae, including a non-pathogen [76]. It is a multiprotein complex (T4Es) allows the bacteria evade host defenses and, to subvert host cell processes to their own advantage [77] (table 2) (fig. 1).

\section{Endosymbionts in soft ticks}

Bacterial endosymbionts of ticks are of interest due to their close evolutionary relationships with tick-vectored pathogens. For instance, whereas many ticks contain Francisella-like endosymbionts (FLEs), others transmit the mammalian pathogen Francisella tularensis [78]. D. variabilis is normally highly resistant to American dog tick (Dermacentor variabilis) tick/fungus association. Harbour Metarhizium anisopliae, a widely-distributed entomopathogenic fungus. Female ticks harbor S. brevicaulisa mycobiont internally [79]. Coxiella burnetii, the logic agent of acute $\mathrm{Q}$ fever and chronic endocarditis, is an intracellular form that occupies a large lysosomederived acidic vacuole. C. burnetiia bacterium grows with in mammalian cells obligate intracellular replication in a hostile manner [80]. Ixodes scapularis and Dermacentor andersoni, infected with an endosymbiont, Rickettsia peacockii Lyme disease spirochete, Borrelia burgdorferi. Rickettsia peacockiiis a non-pathogenic obligate intracellular bacterium found as an endosymbiont in Dermacentor andersoni ticks in the western USA and Canada. Its presence in ticks is correlated with reduced prevalence of Rickettsia rickettsii, the agent of Rocky Mountain spotted fever [81] (table 2).

\section{Biological effects}

Tick saliva exhibits catalytic, vasodilator, anticoagulant, antiinflammatory, and immunosuppressive activity. Salivary fluid also mediates several other biological functions such as secretion of cement and hygroscopic components, as well as the watery component of blood as regards hard ticks. Ixodid tick salivary gland extracts inhibit the production of lipopolysaccharide-induced mRNA of several different human cytokines female Rhipicephalus appendiculatus [82]. RGD-toxin protein, Lj-RGD3 is isolated from the buccal gland secretion of Lampetra japonica. It shows diverse biological activities [83]. Tick saliva contains of blood clotting factors Xa and XIa, trypsin and plasmin that shows antihaemostatic functions (fig. 1).

\section{Effect of blood cells}

Amblyomma americanum tick possesses Serpin19, an inhibitor of blood contains an inhibitor of blood clotting factors Xa and XIa, trypsin and plasmin that shows anti-haemostatic functions (fig. 1). Tick saliva reduces adherence and area of human neutrophils. Saliva of ixodid ticks reduces polymorphonuclear leukocyte (PMN) adhesion via downregulation of $\beta 2$-integrins and decreases the efficiency of PMN in the uptake and killing of spirochetes. Ticks transmit human granulocytic ehrlichiosis caused by obligate intracellular pathogens, Anaplasma phagocytophilum. This organism is unique because it survives and propagates in neutrophil vacuoles [84]. It shows respiratory burst in A. phagocytophilum-infected neutrophils. The ixodid tick Dermacentor marginatus is a vector of many pathogens widespread in Eurasia. Its genes are differentially expressed after blood-feeding and long-term starvation. Ticks as blood-sucking parasites possess specific factors in salivary glands, which act as blood coagulation proteases or specific blood coagulation inhibitors [85]. B-cell inhibitory protein factor found in Ixodes ricinus tick saliva shows a potential role in enhanced Borrelia burgdoferi transmission [86]. Tick, Ornithodoros savignyi also induce paralysis and toxicosis in rats. It salivary gland toxins TSGP4 impose pathological effects on the cardiac system, and cause Mobitz type ventricular block, while TSGP2 induced ventricular tachycardia [87] (table 2) (fig. 1).

\section{Effect on skin cells}

Ticks are hematophagous arthropods which use salivary molecules to ensure their unnoticed and prolonged attachment to the host skin. These attach to host skin for blood-sucking and transmit disease pathogens through saliva. In order to feed, tick chelicerae cut the host epidermis and their hypostome penetrates through the layers of the skin. Tick make cutaneous injury by mouthparts, and inject saliva that inhibits wound healing. Tick soft clinging type attachment helps them to attach 
to biological plug system. The majority of ticks in the family Ixodidae secrete a substance anchoring their mouthparts to the host skin. This substance is termed cement. Ticks salivary secretions cause intense pain and itch, homeostasis, inflammation, innate and adaptive immunity. Tick transmit diverse array of infectious agents they transmit etiological bacterium, Borrelia burgdorferi sensu lato (Bbsl). Cytotoxins of $P$. haemolytica generate fever in sheep and enhance the number of PMN cells [88] (table 2) (fig. 1).

\section{Protease inhibitors}

Protease inhibitors: Serine Protease inhibitors (PIs) are important regulators of physiology and represent anti-parasitic druggable and vaccine targets. Amblyommaa americano and other ixodid tick possess protease inhibitor (PI) repertoire. Tick saliva serine protease inhibitors (serpins) facilitate tick blood meal feeding through the inhibition of protease mediators of host defense pathways. Exists mediate the anti-inflammatory effects of a multifunctional serpent from the saliva of the tick Ixodes ricinus secreted by female $A$. americanum ticks (serpins) are structurally related but functionally diverse family of ubiquitous proteins. Serpin from the saliva of the tick Ixodes ricinus displays high affinity for human leukocyte elastase of act as immunosuppressor (Iris) Iris also displays pleotropic effects because it interferes with both the immune response and hemostasis of the host [89]. Egg-toxins from, Boophilus microplus, Boophilus decoloratus and Hyalomma truncatum were found to be inhibitors of trypsin and in two cases also of chymotrypsin [90]. Protease inhibitors (PIs) are important regulators of physiology and represent anti-parasitic drugs and vaccine targets (table 2) (fig. 1).

\section{Immune responses}

Tick saliva contains a complex mixture of peptides and non-peptides that counteract their hosts' homeostasis, immunity, and tissuerepair reactions. The ixodid ticks salivary glands (SG) secreted saliva contains a rich mixture of anti-hemostatic, anti-inflammatory, and immune modulator anti-coagulatory, anti-vasoconstrictory, and anti-platelet aggregation factors. Tick saliva produces itching or pain and initiate blood-feeding by making an incision in skin cells. Ticks inject toxins which generate cellular and humoral responses. There are thousands of different transcripts have been detected which codes for secreted polypeptides in a single tick species. Ticks bear antigen families evasions, Isac, DAP36, and many others on their surface. Tick salivary cystatin sialostatin L2 suppresses Type I interferon responses in mouse dendritic cells. IFN is produced by dendritic cells (DCs) in response to tick saliva proteins. Sialostatin L (SialoL) is a secreted cysteine protease inhibitor identified in the salivary glands of the Lyme disease vector. Tick solicitation L shows immunomodulatory action on dendritic cells and interfere in autoimmunity. LPS-induced maturation of dendritic cells from C57BL/6 mice get significantly decreased when exposed to SialoL [91] (table 2) (fig. 1).

Tick-borne pathogens cause potent infections. These pathogens generalized modulate host innate and adaptive immune responses. This is called "saliva-activated transmission" and enables tick-borne pathogens to evade host immune responses. Few important salivary components of ticks induce immunomodulation also neutralize elements of innate immunity or inhibit the development of adaptive immunity. Lipopolysaccharide (LPS) stimulates the innate immune response in arthropods. Langerhans cells present tick antigens to lymph node cells tick-sensitized guinea-pigs. Resistance to the feeding activities of ixodid ticks is an acquired, immunologicallymediated phenomenon in guinea-pigs, associated with cutaneous hypersensitivity to tick antigens. Guinea-pig skin cells also showed resistance to D. Anderson larvae due to the generation of cellmediated immune responses.

Tick saliva toxins act as allergens also induce severe IgE-associated allergic reactions, including fatal anaphylaxis, upon subsequent saliva toxin exposure [92]. Ticks secrete holocyclotoxins that triggers host paralysis by causing inhibition of presynaptic nerve cells. These induce severe/toxicoses in their hosts. Borrelia species affect differentiation THP-1 Cells while Ehrlichia chaffeensis an intracellular pathogenic bacterium causes monocytic ehrlichiosis in man [93]. Tick saliva inhibits differentiation, maturation and function of murine bone-marrow-derived dendritic cells More specifically salivary cystatins from the hard tick Ixodes scapularis, sialostatin L (Sialo L) and sialostatin L2 (Sialo L2), influence mouse dendritic cells exposed to Borrelia burgdorferi and relevant Toll-like receptor ligands (table 2).

Ticks as vectors secrete immunosuppressant peptide, and, immunoreactive proteins and antimicrobial peptides which also used in host defense. Its LPS activate expression of immune genes, including those for antibacterial peptides. Few non-coding small RNAs regulate synthesis of these peptides at the post-transcriptional level [94]. Tick harbor rickettsiae that spread spot fever in cattle and human [95]. Rickettsiae produce two immune dominant outer membrane proteins; rickettsial, Omp A (rOmp A) and rOmpB which are strong antigen and could be used for vaccine production. Besides this, ticks secrete hundreds to thousands of proteins into the feeding site in saliva. These salivary components play an important role in the modulation of host defense mechanisms [96]. Few of them neutralize elements of innate immunity or inhibit the development of adaptive immunity. Similar immunomodulatory effects are also caused by Australian tick Ixodes holocyclus in toxicosis. It causes paralysis in domestic animals such as dogs and cats, livestock, and humans. Tick saliva exposed to Borrelia burgdorferi, Anaplasma phagocytophilum dihydrolipoamide dehydrogenase 1 affects host-derived immunopathology during microbial colonization [96]. Similar immunomodulation is also found in other hematophagous arthropod vectors such as mosquitoes, tsetse flies and sand flies which are responsible for pathogen transmission [97]. For treatment of neurologic diseases immunoglobulin therapy is provided [98] (table 2).

A thiomersal-free and albumin-free tick-borne encephalitis-vaccine (TBE-vaccine) was developed in Australia 2000 for the treatment of tick borne toxicosis [99]. Monoclonal antibodies synthesized against single antigen are used to neutralize paralysis toxin of Rhipicephalus evertsi evertsi, Rhipicephalus appendiculatus, Boophilus microplus and Ixodes holocyclus ticks [100]. A recombinant veterinary vaccine is also developed to neutralize the effect of tick neurotoxin peptide sequence. Though, this vaccine is successful, cost-effective, and provides long-term protective immunity against tick-induced paralysis [101]. The vaccine is also administered to decrease the Lyme disease incidences [102]. However, for the development of vaccines or protection against Anaplasma marginale type IV secretion system proteins VirB2, VirB7, VirB11, and VirD4 are used as immunogenic components. These show effective serological responses in man [103]. Other approaches (ivermectin) are also tried for the development of tick vaccines for prophylactic use [104]. In present time for treatment of tick paralysis polyclonal dog antiserum is provided for prophylaxis (table 2).

For the immunization of cattle, an Anaplasma marginale fraction enriched the outer membranes (OM) is used, it provides complete protection against disease and persistent infection. However, for the preparation of an appropriate vaccine complete genome sequencing of bacterial parasites is essential to identify the type IV secretion system (T4SS) [105]. This highly distinctive type IV secretion system stays as neurotoxins found in tick saliva [106]. More specifically, a surface protein with $_{3}$ aintegrin binding and channel forming activities responsible for Borrelia burgdorferi [107] and a plasminogen receptor BosR (BB0647) released in outer membrane of Borrelia burgdorferi governs virulence expression could be used as antigen [108]. Nitric oxide also function as an antimicrobial effector molecule, it is produced by activating mouse macrophages in response to viral infection. It is implicated in antiviral defense mainly against flaviviruses [109]. It is a potent microbicidal and tumoricidal agent (fig. 1).

\section{Diagnosis}

Tick has borne abnormalities and infections such as spotted fever caused by rickettsiasis can be identified by LPS lipopolysaccharides antigenicity. Lyme disease caused by ticks is identified by diagnosing samples on SDS-PAGE gel electrophoresis, enzyme-linked immunosorbent assay (ELISA) and immunoblotting [110]. These are also diagnosed by measuring the level of the Immunoglobulin G1 isotype [111]. Western black-legged tick Ixodes pacificus (Acari: 
Ixodidae) was isolated from feeding on naturally infested dogs from Eastern Austria. Theileria lestoquardi, T. ovis and T. annulata are detected by molecular methods in the blood of Goats and Ticks. The identification and functional characterization of tick saliva proteins can be useful to elucidate the molecular mechanisms involved in tick development and to conceive new anti-tick control methods. Mast cells and IgE levels are used to detect tick-borne allergy (fig. 1).

\section{Control}

For tick control, few conventional tick control methods such as spray with chemical acaricides, household disinfectants such as Jeyes fluid, engine oil, chickens (5.1\%), manual removal (5.1\%), and pouricides $(1.7 \%)$ are used. Farmers also Aloe ferox leaves and bark of Ptaeroxylon obliquum for the killing of ticks. Farmers collect ticks by handpicking and kill by dumping them in kerosene oil. For regular tick prophylactic treatment DDT, flumethrin, Bayticol ${ }^{\circledR}$ are used at a large scale (table 3) (fig. 2). Though, these are highly toxic to animals and humans. The synthetic pyrethroid insecticide phenothrin is in combination with the hormone analogue methoprene topically applied to flea and ticks. Phenothrin kills adult ticks, while methoprene kills eggs. Phenothrin kills adult ticks while Methoprene is used to kill ticks eggs. Flumeltrin B atical ${ }^{\circledR}$ Peptide toxin and Nitric oxide are effective in tick-killing. Bifenthrin and permethrin, both pyrethroids, are also used to control ticks measures. Besides these, few residual insecticides, FenvaStarEcoCap, Bifen IT, or Precor2000 Plus Aerosol, FenvaStarEcoCap, Bifen IT, or Precor2000 Plus Aerosol are also to kill ticks. For the quick killing of ticks' non-residual, contact space sprays that contain pyrethrins are used. Natural tick repellents are also used for the cultural management of ticks (table 3) (fig. 2).
These highly toxic synthetic acaricides show several negative side effects because they bio-accumulate at each stage and impose toxicity to non-target organisms/animals. Tick population also developed resistance against these chemicals [112]. Hence, various latest strategies are adopted for the prevention of tick and tickborne illness. Few tick avoidance, vector reduction programs, chemoprophylaxis, and natural repellents of ticks are used [113]. For control of tick population, Tekko Pro IGR is used to stop development in immature ticks.

Ticks such as Rhipicephalus turanicus are controlled by using acaricidal plant products [114]. Few antibiotics were found effective against some ticks, mainly blue ticks. These are carcinogenic and also attack the nervous systems of other species. RNAi-mediated gene silencing is also used to block gene regulation of saliva toxins. This RNAi-mediated gene silencing in tick cells is used to genetically regulate the tick population (table 3) (fig. 2).

Bacillus thuringiensis (Bt) bio-insecticidal toxins are also used to kill ticks and its associating pathogens. Entomopathogenic fungi spores also control ticks mainly at enzootic or epizootic levels in their host populations. But for the use of bio-insecticides and other chemicals licensed applicators are required [115] because they show cytotoxicity in human osteosarcoma cells [116], damage membrane and obstruct organ functions [117]. Efforts should be made for their targeted release, low exposure period and safe use [118]. Ticks possess unique natural compounds which show multiple biological activities [119] much similar to defense molecules found in other animal groups mainly venomous [120,121]. For cultural control of ticks safe land-use has an influence on exposure to tick-borne pathogens that can be exploited for disease control (table 3) (fig. 2).

Table 1: Important pathogenic diseases transmitted by ticks

\begin{tabular}{|c|c|c|c|}
\hline Diseases & Pathogen or causal agent & Tick vector & Source \\
\hline Analplasma granulocytosis & Anaplasma & I. scapularis, I. pacificus & [37] \\
\hline Rocky Mountain spotted fever & Rickettsia & D. variabilis, D. andersoni & [51] \\
\hline Colorado tick fever & CTF virus & D. andersoni & [53] \\
\hline Babesiosis & Babesia & I. scapularis, I. pacificus & {$[57]$} \\
\hline Tick paralysis & Toxin & D. variabilis, D. andersoni & [61] \\
\hline Tick-borne Relapsing Fever & Borrelia species & Ornithodoros species ticks & [62] \\
\hline Powassan encephalitis & Powassan & I. cookei & [67] \\
\hline Ehrlichiosis. monocytic & Ehrlichia & A. americanum & [72] \\
\hline Lyme disease & Borrelia & I. scapularis, I. pacificus & [75] \\
\hline Southern rash illness & Borrelia & A. americanum & [76] \\
\hline Tularemia & Franciscella & D. variabilis, A. americanum & [78] \\
\hline
\end{tabular}

Table 2: Important tick borne diseases in man and livestock

\begin{tabular}{|c|c|c|c|}
\hline Vector & Name of disease & Pathogen/Parasite & Source \\
\hline \multicolumn{4}{|l|}{ Protozoan diseases } \\
\hline H. anatolicum, $R$. appenticulatus & Theileriosis & Theileriaannulata, T. parva, T. hirci & {$[50]$} \\
\hline R. (B.) microplus. & Babesiosis & B. bigemina, B. ovis & [63] \\
\hline Haemaphysalisspp & Babesiosis & B. motasi & {$[66]$} \\
\hline H. anatolicum & Babesiosis & B. equi & [66] \\
\hline Ixodes spp. & Human Babesiosis & B. divergens & {$[66]$} \\
\hline \multicolumn{4}{|l|}{ Viral diseases } \\
\hline Hyalommaa natolicum & Crimean-Congo haemorragic fever & Nirovirus (Bunyaviridae) & \\
\hline Haemophysalisspi nigera & Kyasanur Forest Disease & Group B Toganvirus (Flavidiridae) & {$[75]$} \\
\hline Ornithodorus mobuta & African swine fever & African swine fever virus & [75] \\
\hline Hyalomma dromedarii & African horse sickness & Reoviridae (African horse sickness virus) & {$[75]$} \\
\hline Rhipicephalus sanguine & $\begin{array}{l}\text { Ehrlichiosis, Human monocytic } \\
\text { Ehrlichiosis }\end{array}$ & $\begin{array}{l}\text { Ehrlich iacanis, E. equi } \\
\text { E. chaffeensis, E. senetsu E. phagocytophilia }\end{array}$ & [75] \\
\hline \multicolumn{4}{|l|}{ Bacterial diseases } \\
\hline Dermacentor spp. & Tularemia & Francisellatularensis & [78] \\
\hline $\begin{array}{l}\text { Rhipicephalus appendiculatus } \\
\text { Spirochete diseases }\end{array}$ & Nairobi sheep disease & Bunyaviridae & {$[82]$} \\
\hline Ixodes ricinus & $\begin{array}{l}\text { Lyme disease } \\
\text { Rickettsial diseases }\end{array}$ & 90.90.90.90 Borreliaburgdorferi & {$[86]$.} \\
\hline Amblyoma variegatum & Cowdriosis Anaplasmosis & Cowdriaruminantium Anaplasmamarginale & \\
\hline $\begin{array}{l}\text { R. sanguineus, Dermacenter andersoni, } \\
R(B .) \text { decoloratus }\end{array}$ & Indian tick typhus (ITT) & Rickettsia conorii & \\
\hline
\end{tabular}


Table 3: Most commonly used acaricides for the control of ticks in the residential landscape

\begin{tabular}{|c|c|c|c|}
\hline Chemical & Some brand or common names* & Chemical type and usage & Source \\
\hline Permethrin & $\begin{array}{l}\text { Astro® Ortho® products Bonide } ₫ \text { products } \\
\text { Tengard@ SFR Others }\end{array}$ & Pyrethroid insecticide used in spray & [111] \\
\hline Pyrethrin & $\begin{array}{l}\text { Pyrenone } ₫ \text { Kicker } \AA \text { organic solutions all crop } \\
\text { commercial and agricultural multipurpose } \\
\text { Insecticide } \AA\end{array}$ & $\begin{array}{l}\text { Natural pyrethrins with the synergist piperonylbutoxide } \\
\text { (PBO) or insecticidal soap are highly effective against } \\
\text { ticks }\end{array}$ & {$[111]$} \\
\hline Carbaryl & Sevin $\AA$ & Carbamate insecticide a common garden insecticide & {$[115]$} \\
\hline Cynuthrin & Tempo® Powerforce ${ }^{T M}$ & Pyrethroid insecticide used in spray & [116] \\
\hline Deltramethrin & Suspend $\AA$ DeltaGard $® G$ & Pyrethroid insecticide used in spray & {$[117]$} \\
\hline lambda-cyhalothrin & Scimitar $\AA$ Demand $\AA$ & Pyrethroid insecticide used in spray & [118] \\
\hline
\end{tabular}

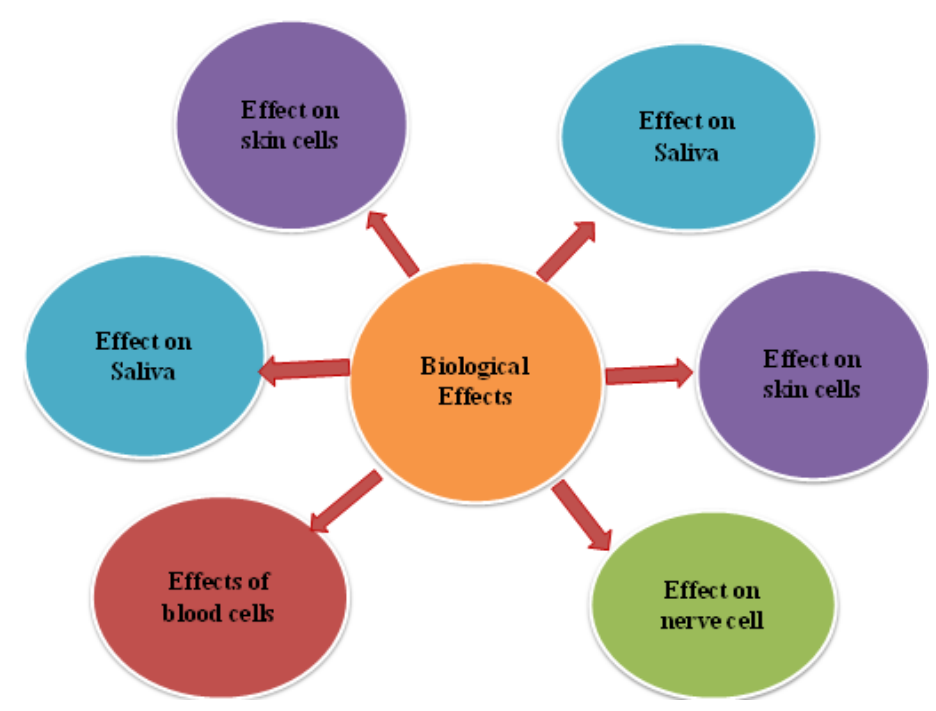

Fig. 1: Showing biological effects of tick saliva toxins

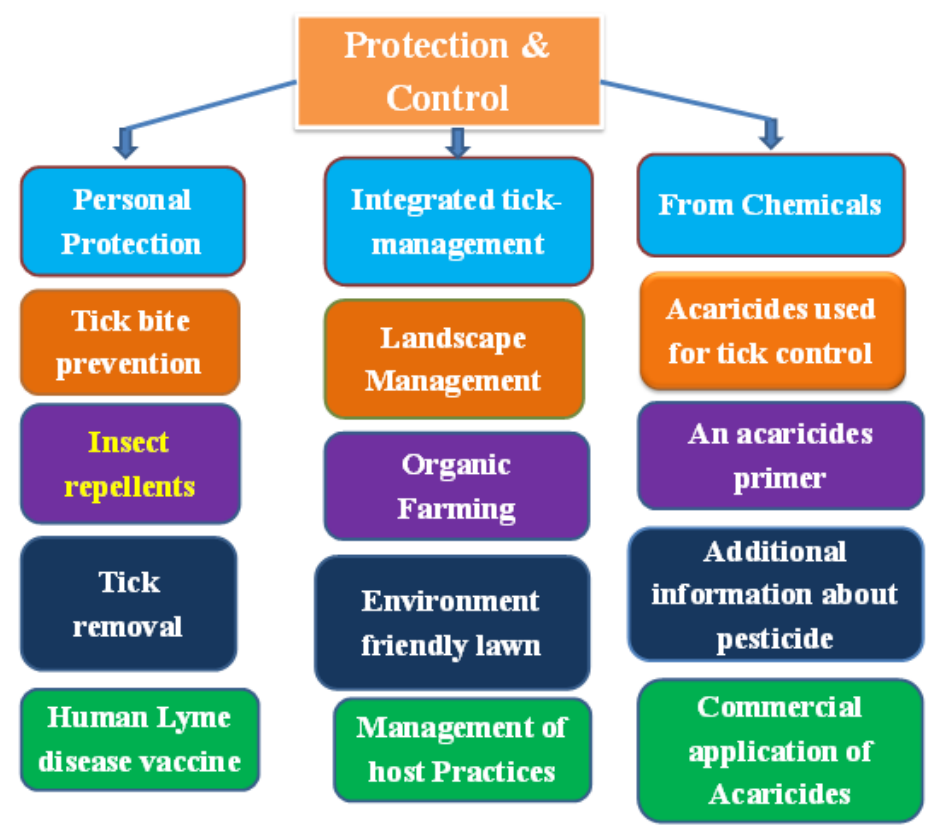

Fig. 2: Showing different control methods of tick population

\section{Precautions}

Wash pet bedding or discard their bedding. Clean area rugs, Steam clean or vacuum furniture where pets rest. Ticks like to reside in crack and crevices; they seek hiding areas for safety, behind baseboards. Fumigate and keep clean window and doormats, frames, and curtains. Regularly spray and bath pets for regular tick treatment. Keep pastures short by grazing or mowing to minimize vegetation where ticks could live.

\section{CONCLUSION}

Ticks are major vectors which transmit a diverse group of pathogens and evoke diseases in livestock and make huge losses to veterinary, 
animal farms, pets and wildlife animals worldwide. Ticks harbor a wide variety of pathogenic, pathogenic and endosymbiotic microorganisms and transmit them to vertebrate hosts. They cause direct economic losses; hence, their control is an important issue. For tick control conventional tick control methods such as spray with chemical acaricides, household disinfectants and pouricides are largely used. For prophylactic treatment of ticks DDT, flumethrin, Bayticol@Farmers are used at a large scale. Though, these are highly toxic to animals and humans. The synthetic pyrethroid insecticide phenothrin is in combination with the hormone analogue methoprene topically applied to flea and ticks. Peptide toxin and Nitric oxide are effective in tick-killing. Bifenthrin and permethrin, both pyrethroids, are also used to control ticks measures. For the quick killing of tick population pyrethrins are used. Natural tick repellents are also used for the cultural management of ticks. These highly toxic synthetic acaricides show several negative side effects.

For control, strict quarantine measures are enforced to prevent reintroductions of ticks with goods and materials ferried or parceled among countries. For the killing of ticks natural oils, bioinsecticides in form Bt toxins are used. For the safety of man and his livestock vaccines are used. For successful control, various models of tick population dynamics is required for predicting outcomes of control methods. It also need better understanding of drivers of distribution, aggregation, stability, and density-dependent mortality. Climatematching models, geographic information systems, and expert systems mainly subject experts and artificial intelligence are being used to identify unaffected areas in which tick pests could become established if introduced. A current, promising strategy is the identification of receptor sites on the midgut of vector ticks and the development of antibodies that bind with these sites, thereby blocking tick-ingested tick-borne pathogens from infecting the tick. Cattle injected with receptor-site antigens may produce antibodies that feeding ticks ingest. Few broad-spectrum antibiotics and vaccines effectively work against tick-borne infection.

\section{ACKNOWLEDGEMENT}

Authors are thankful to H. O. D., Department of Zoology for research facilities.

\section{FUNDING}

Nil

\section{AUTHORS CONTRIBUTIONS}

Ravi Kant Upadhyay and Nidhi Yadav were responsible for conception, literature review, writing and revising the manuscript.

\section{CONFLICT OF INTERESTS}

The authors declare no competing financial interests.

\section{REFERENCES}

1. Sonenshine DE. Biology of ticks. Vol. 1. Oxford University Press: New York; 1991.

2. Guglielmone Alberto A, Richard G Robbins, Dmitry A Apanaskevich, Trevor N Petney, Agustin Estrada Pena. The argasidae, ixodidae and nuttalliellidae (Acari: Ixodida) of the world. List Valid Species Names: Zootaxa 2010;2528:1-28.

3. Snelson JT. Animal ectoparasites and disease vector causing major reduction in world food supplies. FAO Plant Protection Bulletin 1975;13:103-14.

4. Horak IG, Camicas JL, Keirans JE. The argasidae, ixodidae and nuttalliellidae (Acari: Ixodida): a world list of valid tick names. Exp Appl Acarol 2002;28:27-54.

5. Nava S, Venzal JM, Terassini FA, Mangold AJ, Camargo LM, Labruna MB. Description of a new argasid tick (Acari: Ixodidae) from bat caves in Brazilian Amazon. J Parasitol 2010;96:1089-101.

6. Apanaskevich DA, Horak IG, Matthee CA, Matthee S. A new species of Ixodes (Acari: Ixodidae) from South African mammals. J Parasitol 2011;97:389-98.

7. Peter J Krause. Human babesiosis. Int J Parasitol 2019;49:165-74.

8. Mans BJ, De Klerk D, Pienaar R, Latif AA. (Nuttalliell anamaqua): a living fossil and closest relative to the ancestral tick lineage: implications for the evolution of blood-feeding in ticks. PloS One 2011;6:e23675.
9. Dantas Torres F, Venzal JM, Bernardi LF, Ferreira RL, Onofrio VC, Marcili A, et al. Description of a new species of batassociated argasid tick (Acari: Argasidae) from Brazil. J Parasitol 2012;98:36-5.

10. Estrada Pena A, Venzal JM, Nava S, Mangold A, Guglielmone AA, Labruna MB, et al. Reinstatement of Rhipicephalus (Boophilus) australis (Acari: Ixodidae) with redescription of the adult and larval stages. J Med Entomol 2012;49:794-802.

11. Heath AC. A new species of soft tick (Ixodoidea: Argasidae) from the New Zealand lesser short-tailed bat, (Mystacina tuberculata) gray. Tuhinga. Te Papa Museum New Zealand 2012;23:29-7.

12. Venzal J, Nava S, Mangold A, Mastropaolo M, Casas G, Guglielmone A. Ornithodoros quilinensis sp. nov. (Acari, Argasidae), a new tick species from the Chacoan region in Argentina. Acta Parasitol 2012;57:329-36.

13. Apanaskevich DA, Horak IG, Mulumba Mfumu LK. A new species of Rhipicephalus (Acari: Ixodidae), a parasite of red river hogs and domestic pigs in the democratic republic of congo. J Med Entomol 2013;50:479-84.

14. Venzal J, Nava S, Mangold A, Mastropaolo M, Casas G, Guglielmone A. A new species of Ornithodoros (Acari: Argasidae), parasite of Microlophus spp. (Reptilia: Tropiduridae) from northern Chile. Ticks Tick Borne Dis 2013;4:128-32.

15. Oliver JH. Jr Biology and systematics of ticks (Acari: Ixodida). Annu Rev Ecol Syst 1989;20:397-30.

16. Fuente Jde la, Estrada Pena A, Venzal JM. Ticks as vectors of pathogens that cause disease in humans and animals. Front Biosci 2008;13:6938-46.

17. FAO Ticks and ticks borne disease control. A practical field manual. Vol. 1. Tick control. F. A. O. Rome; 1984. p. 299.

18. Geevarghese G, Fernandes S, Kulkarni SMA. Checklist of Indian ticks (Acari: Ixodidae). Indian J Anim Sci 1997;67:566-74.

19. Rajamohanan K. Studies on the common ticks affecting livestock in Kerala: Ph. D. Dissertation. Kerala Agricultural University, Thrissur; 1980.

20. Prakasan K, Ramani N. Tick parasites of domestic animals of Kerala, South India. Asian J Anim Vet Adv 2007;2:74-80.

21. Woodward TE, DH Walker, JS Dumler. The remarkable contributions of S. Burt Wolbach on rickettsialvasculitis updated. Trans Am Clin Climatol Assoc 1992;103:78-94.

22. Zhou Wenshuo, Faizan Tahir, Joseph Che Yen Wang, Woodson M, Michael B Sherman, Karim S, et al. Discovery of exosomes from tick saliva and salivary glands reveals therapeutic roles for CXCL12 and IL-8 in wound healing at the tick-human skin interface. Front Cell Dev Biol 2020;8:554.

23. Common Ticks. Illinois Department of Public Health; 2014.

24. Nicholson WL, Sonenshine DE, Noden BH, Brown RN. Ticks (Ixodida)". In: Mullen G, Durden L. eds. Medical and Veterinary Entomology. Academic Press; 2009. p. 483-32.

25. Hard ticks. CVBD: Companion Vector-Borne Diseases; 2016.

26. Walker JB, Keirans JE, Horak IG. The genus Rhipicephalus (Acari, Ixodidae): a guide to the brown ticks of the world: Cambridge University Press; 2005. p. 39.

27. Salman MD, Tarres Call J, Estrada Pena. A ticks and tick-borne diseases: geographical distribution and control strategies in the Euro-Asia region. CABI; 2013. p. 6-12.

28. Ann L Carr, Vincent L Salgado. Ticks home in on body heat: a new understanding of Haller's organ and repellent action. PLoS One 2019;23:221659.

29. Buysse M, Plantard O, McCoy KD, Duron O, Menard C. Tissue localization of coxiella-like endosymbionts in three European tick species through fluorescence in situ hybridization. Ticks Tick-Borne Diseases 2019;10:798-804.

30. Balashov YS. Bloodsucking ticks (Ixodoidea) vectors of disease of man and animals: College Park MD: Entomol Society of America; 1972.

31. Binetruy F, Buysse $M$, Lejarre $\mathrm{Q}$, Barosi R, Villa M, Rahola N, et al. Microbial community structure reveals the instability of nutritional symbiosis during the evolutionary radiation of Amblyomma ticks. Mol Ecol 2020;29:1016-29.

32. Duron O, Binetruy F, Noel V, Cremaschi J, McCoy KD, Arnathau $\mathrm{C}$, et al. "Evolutionary changes in symbiont community structure in ticks. Mol Ecol 2017;26:2905-21. 
33. Rabinowitz PM, Conti LA. Zoonoses. Human-Animal Medicine; 2010. p. 105-98.

34. Ruppert EE, Fox RS, Barnes RD. Invertebrate zoology. $7^{\text {th }}$ ed. Cengage Learning; 2004. p. 590-5.

35. Smith TA, Driscoll T, Gillespie JJ, Raghavan R. A coxiella-like endosymbiont is a potential vitamin source for the lone star tick. Genome Biol Evol 2015;23:831-8.

36. Duron O, Sidi Boumedine K. The importance of ticks in q fever transmission: what has (and has not) been demonstrated? Trends Parasitol 2015;31:536-52.

37. Murray $\mathrm{W}$ Lankester, $\mathrm{W}$ Brad Scandrett. Experimental transmission of bovine anaplasmosis (caused by Anaplasmamarginale) by means of Dermacentor variabilis and D. andersoni(Ixodidae) collected in western Canada. Can J Vet Res 2007;71:271-7.

38. Sori Teshale, Dirk Geysen, Gobena Ameni. Survey of Anaplasma phagocytophilum and anaplasma sp: 'Omatjenne' infection in cattle in Africa with special reference to Ethiopia. Parasit Vectors 2018;11:162.

39. Duron O, Sidi Boumedine K. The importance of ticks in q fever transmission: what has (and has not) been demonstrated? Trends Parasitol 2015;31:536-52.

40. Jongejan F, G Uilenberg. Ticks and control methods. Rev Sci Tech 1994;13:1201-26.

41. Natoshi Badgar Battsetseg, Damdinsuren Boldbaatar, Takeharu Miyoshi, Xuenan Xuan, James H Oliver Jr, Kozo Fujisaki Babesial. Vector tick defensin against babesia sp: parasite. Infect Immun 2007;75:3633-40.

42. Guizzo MG, Parizi LF, Nunes RD, Schama R, Albano RM, Tirloni L, et al. A Coxiella mutualists ymbiont is essential to the development of Rhipicephalus microplus. Sci Rep 2017;7:17554.

43. Ben Yosef M, Rot A, Mahagna M, Kapri E, Behar A, Gottlieb Y, et al. Rhipicephalussanguineus is required for physiological processes during ontogeny. Front Microbiol 2020;11:493.

44. Randolph SE, Randolph SE, Green RM, Hoodless AN, Peacey MF. An empirical quantitative framework for the seasonal population dynamics of the tick Ixodes ricinus. Int J Parasitol 2002;32:979-89.

45. Walker AR. Age structure of a population of Ixodes ricinus (Acari: Ixodidae) in relation to its seasonal questing. Bull Entomol Res 2001;91:69-78.

46. Robert S Lane, Jeomhee Mun, Harrison A Stubbs Horizontal. Horizontal and vertical movements of host-seeking Ixodespacificus (Acari: Ixodidae) nymphs in a hardwood forest. J Vector Ecol 2009;34:252-66.

47. Pienaar Ronel, Albert WH Neitz Ben J Mans. Tick paralysis: solving an enigma. Vet Sci 2018;14:53.

48. Katarina Wallmenius, Christos Barboutis, Albert WH, Neitz Ben J Mans, Albert WH, Neitz Ben J Mans, et al. Spotted fever Rickettsia species in Hyalomma and Ixodes ticks infesting migratory birds in the European Mediterranean area. Parasit Vectors 2014;7:318.

49. J Rehacek, B Kaaserer, J Urvolgyi M Lukacova, E Kovacova, E Kocianova. Isolation of coxiellaburnetii and of an unknown rickettsial organism from Ixodes ricinus ticks collected in Austria. Eur J Epidemiol 1994;10:719-23.

50. Sager H, C Brunschwiler, TW Jungi. Interferon production by Theileria annulata-transformed cell lines is restricted to the beta family. Parasite Immunol 1998;20:175-82.

51. Magnarelli LA. Global importance of ticks and associated infectious disease agents. Clin Microbiol Newsletter 2009;31:33-7.

52. Nuttall GH. Ticks and tick-transmitted diseases. Transactions of the Epidemiological Society of London; 1905;24:12-6.

53. Dantas Torres F, Oliveira Filho EF. Ticks infesting amphibians and reptiles in Pernambuco, Northeastern Brazil. Brazilian J Veterinary Parasitol 2008;17:218-21.

54. M Ruppin, S Sullivan, F Condon, N Perkins, L Lee, LB Jeffcott, et al. Retrospective study of 103 presumed cases of tick (Ixodes holocyclus) envenomation in the horse Aust. Vet J 2012;90:175-80.

55. Dawn R Clifton, Elena Rydkina, Robert S Freeman, Sanjeev K Sahni, NF-kappa B. Activation during rickettsia rickettsii infection of endothelial cells involves the activation of catalytic Ikappa B kinases IKKalpha and IKKbeta and phosphorylation- proteolysis of the inhibitor protein Ikappa Balpha. Infect Immun 2005;73:155-65.

56. James G Fox, Christian E. Newcomer, and harry rozmiarek. Selected Zoonoses Laboratory Animal Medicine; 2002. p. 1059-105.

57. Hiroki Maeda, Takeshi Hatta, M Abdul Alim, Daigo Tsubokawa, Fusako Mikami, Makoto Matsubayashi, et al. Establishment of a novel tick-Babesia experimental infection model. Sci Rep 2016;6:37039.

58. Chaudhuri S, JP Varshney. Clinical management of babesiosis in dogs with homeopathic crotalushorridus200c. Homeopathy 2007;96:90-4.

59. Nabiha Huq Saifee, Peter J Krause, Yanyun Wu. Apheresis for babesiosis: therapeutic parasite reduction or removal of harmful toxins or both? J Clin Apher 2016;31:454-8.

60. Mans BJ, Gothe R, Neitz AWH. Biochemical perspectives on paralysis and other forms of toxicoses caused by ticks. Parasitology 2004;129:95-11.

61. Hall Mendelin S, SB Craig, RA Hall, PO Donoghue, RB Atwell, SM Tulsiani, et al. Tick paralysis in Australia caused by Ixodes holocyclus Neumann. Ann Trop Med Parasitol 2011;105:95-106.

62. William K Boyle, Hannah K Wilder, Amanda M Lawrence, Job E Lopez. Transmission dynamics of Borrelia turicatae from the arthropod vector. PLoS Negl Trop Dis 2014;8:2767.

63. Patricia Silva Golo, Isabele da Costa Angelo, Mariana Guedes Camargo, Wendell Marcelo de Souza Perinotto, Vania Rita Elias Pinheiro Bittencourt. Effects of destruxin A on Rhipicephalus (Boophilus) microplus ticks (Acari: Ixodidae). Rev Bras Parasitol Vet 2011;20:338-41.

64. Safronetz David, Heinz Feldmann. animal models of tickborne hemorrhagic feverviruses marko zivcec. Pathogens 2013;2:402-21.

65. Sanchez M, M Venturini, A Blasco, T Lobera, B Bartolome, JA Oteo, et al. Tick bite anaphylaxis in a patient allergic to bee venom. J Investig Allergol Clin Immunol 2014;24:284-5.

66. Jeremy S Gray, Olaf Kahl, Robert S Lane, Michael L Levin, Jean I Tsao. Diapause in ticks of the medically important Ixodes ricinus species complex. Ticks Tick Borne Dis 2016;7:992-1003.

67. Syed Soheb Fatmi, Rija Zehra, David O Carpenter. Powassan virus-a new reemerging. Tick-Borne Disease 2017;5:992-1003.

68. Mizuki Sakai, Kentaro Yoshii, Yuji Sunden, Kana Yokozawa, Minato Hirano, Hiroaki Kariwa, et al. Variable region of the 3' UTR is a critical virulence factor in the FarEastern subtype of tick-borne encephalitis virus in a mouse model. Front Public Health 2014;95:823-35.

69. Ivo MB Francischetti, Zhaojing Meng, Ben J Mans, Nanda Gudderra, Mark Hall, Timothy D Veenstra, et al. An insight into the salivary transcriptome and proteome of the soft tick and vector of epizootic bovine abortion, Ornithodoro scoriaceus. J Proteomics 2008;71:493-12.

70. Telleasha L Greay, Alexander W Gofton, Andrea Paparini, Una M Ryan, Charlotte L Oskam, Peter J Irwin. Recent insights into the tick microbiome gained through next-generation sequenceing. Parasit Vectors 2018;11:12.

71. Marcelino Isabel, Miguel Ventosa, Elisabete Pires, Markus Müller, Frederique Lisacek, Thierry Lefrançois, et al. Comparative proteomic profiling of Ehrlichia ruminantium pathogenic strain and its high-passaged attenuated strain reveals virulence and attenuation-associated proteins. Plos One 2015;10:145328.

72. Noroy Christophe Damien F Meyer. Comparative genomics of the zoonotic pathogen Ehrlichia chaffeensis reveals candidate type IV effectors and putative host cell targets. Front Cell Infect Microbiol 2017;6:204.

73. Mostafa Saleh Mohammad Saleh, Ayman TA Morsy, Mousa AM Ismail, Tosson A Morsy. Tick-borne infectious diseases with reference to Egypt. J Egypt Soc Parasitol 2016;46:273-98.

74. Kenedy Melisha R, Tiffany R Lenhart, Darrin R Akins. The role of Borrelia burgdorferi outer surface proteins. FEMS Immunol Med Microbiol 2012;66:1-19.

75. Hayes SF, W Burgdorfer, A Aeschlimann. Sexual transmission of spotted fever group rickettsiae by infected male ticks: detection of rickettsiae in immature spermatozoa of Ixodes ricinus. Infect Immunol 1980;27:638-42.

76. StokesJohn V, Gail M Moraru, Chelsea McIntosh, Evangel Kummari, Keiko Rausch, Andrea S Varela Stokes, et al. 
Differentiated THP-1 cells exposed to pathogenic and nonpathogenic borrelia species demonstrate minimal differences in production of four inflammatory cytokines. Vector Borne Zoonotic Dis 2016;16:691-5.

77. Hu E, Meng Y, Ma Y. De novo assembly and analysis of the transcriptome of the Dermacentor marginatus genes differentially expressed after blood-feeding and long-term starvation. Parasites Vectors 2020;13:563.

78. Gerhart Jonathan G,H Auguste Dutcher, Amanda E Brenner, Abraham S Moses, Libor Grubhoffer, Rahul Raghavan, et al. Multiple acquisitions of pathogen-derived francisella endosymbionts in soft ticks: genome. Biol Evol 2018;10:607-15.

79. YoderJay A, Joshua B Benoit, David L Denlinger, Justin L Tank, Lawrence W Zettler. An endosymbiotic conidial fungus, Scopulariopsis brevicaulis, protects the American dog tick, Dermacentor variabilis, from desiccation imposed by an entomopathogenic fungus. J Invertebr Pathol 2008;97:119-27.

80. Moses Abraam S, Jess A Millar, Matteo Bonazzi, Paul A Beare, Rahul Raghavan. Horizontally acquired biosynthesis genes boost Coxiella burnetii's physiology. Front Cell Infect Microbiol 2017;10:174.

81. Felsheim Roderick F, Timothy J Kurtti, Ulrike G Munderloh. Genome sequence of the endosymbiont rickettsia peacockii and comparison with virulent Rickettsia rickettsii: identification of virulence factors. Plos One 2009;4:8361.

82. Fuchsberger N, M Kita, V Hajnicka, J Imanishi, M Labuda P. A Nuttall Ixodid tick salivary gland extracts inhibit production of lipopolysaccharide-induced mRNA of several different human cytokines. Exp Appl Acarol 1995;19:671-6.

83. Wang Xiaoxi Jihong Han, Hsinshen Yang, $\mathrm{Li} \mathrm{Lu}, \mathrm{Yu} \mathrm{Wu}, \mathrm{Xin}$ Liu, Renyong Guo, et al. A novel RGD-toxin protein, Lj-RGD3, from the buccal gland secretion of Lampetra japonica impacts diverse biological activities. Biochimie 2010;92:1387-96.

84. Choi, Kyoung Seong J Stephen Dumler. Early induction and late abrogation of respiratory burst in A. phagocytophilum-infected neutrophils. Ann N Y Acad Sci 2003;990:488-93.

85. Monteiro Robson Q. Targeting exosites on blood coagulation proteases. Acad Bras Cienc 2005;77:275-80.

86. Hannier, Sigridjanet Liversidge, Jeremy M Sternberg, Alan S Bowman. Characterization of the B-cell inhibitory protein factor in Ixodes ricinus tick saliva: a potential role in enhanced Borrelia burgdoferi transmission: transmission: Immunol 2004;113:401-8.

87. Mans Ben J, Jose MC Ribeiro. Function mechanism and evolution of the moubatin-clade of soft tick lipocalins. Insect Biochem Mol Biol 2008;38:841-52.

88. Maria Kazimirova, Maria Kazimirova. Tick salivary compounds: their role in modulation of host defences and pathogen transmission. Front Cell Infect Microbiol 2013;3:43.

89. Prevot Pierre Alain Beschin, Laurence Lins, Jerome Beaufays, Amelie Grosjean, Lea Bruys, Benoit Adam, et al. Exosites mediate the anti-inflammatory effects of a multifunctional serpin from the saliva of the tick Ixodes ricinus. FEBS J 2009;276:3235-46.

90. Vermeulen NM, GJ Viljoen, JD Bezuidenhout, L Visser, AW Neitz. Kinetic properties of toxic protease inhibitors isolated from tick eggs. Int J Biochem 1988;20:621-31.

91. Sa Nunes Anderson, Andre Bafica, Lis R Antonelli, Eun Young Choi, Ivo MB Francischetti. The immunomodulatory action of sialostatin $\mathrm{L}$ on dendritic cells reveals its potential to interfere with autoimmunity. J Immunol 2009;182:7422-9.

92. Galli Stephen J, Philipp Stark Thomas Marichal, Mindy Tsai. Mast cells and IgE in defense against venoms: Possible "good side" of allergy? AllergolInt 2016;65:3-15.

93. Noroy Christophe, Damien F Meyer. Comparative genomics of the zoonotic pathogen Ehrlichia chaffeensis reveals candidate type IV effectors and putative host cell targets. Front Cell Infect Microbiol 2017;25:204

94. Wang Haiyan Fangfang Gong, Houshuang Zhang Yongzhi Zhou, Jie Cao, Jinlin Zhou. Lipopolysaccharide-induced differential expression of miRNAs in male and female Rhipicephalus haemaphysaloides ticks. Plos One 2015;2:139241.

95. Noriea Nicholas F, Tina R Clark, Ted Hackstadt. Targeted knockout of the Rickettsia rickettsii Omp A surface antigen does not diminish virulence in a mammalian model system. mBio 2015;31:e00323-15.

96. Chen Gang, Maiara S Severo, Olivia S Sakhon, Anthony Choy, Michael J Herron, Roderick F Felsheim, et al. Anaplasma phagocytophilum dihydrolipoamide dehydrogenase 1 affects host-derived immunopathology during microbial colonization. Infect Immunol 2012;80:3194-205.

97. Cavassani Karen A, Julio C Aliberti, Alexandra RV Dias, Joao S Silva, Beatriz R Ferreira Tick. Tick saliva inhibits differentiation, maturation and function of murine bone-marrow-derived dendritic cells. Immunology 2005;114:235-45.

98. Berlit P. Immunoglobulin therapy in neurologic diseases. Klin Wochenschr 1989;2:967-70.

99. Marth B Kleinhappl E. Albumin is a necessary stabilizer of TBEvaccine to avoid fever in children after vaccination. Vaccine 2001;20:532-7.

100. Crause JC, JA Verschoor, J Coetzee, HC Hoppe, JN Taljaard. The localization of a paralysis toxin in granules and nuclei of prefed female Rhipicephalus evertsi evertsi tick salivary gland cells. Exp Appl Acarol 1993;17:357-63.

101. Masina S, KW Broady. Tick paralysis: development of a vaccine. Int J Parasitol 1999;29:535-41.

102. Schnell Gilles, Nathalie Boulanger, Elody Collin, Cathy Barthel, Sylvie De Martino, Laurence Ehret Sabatier, et al. Proteomic analysis of three Borrelia burgdorferi sensulato native species and disseminating clones: relevance for Lyme vaccine design. Infect Immunol 2015; 15:1280-90.

103. Sutten Eric L, Junzo Norimine, Paul A Beare, Robert A Heinzen, Job E Lopez, Kaitlyn Morse, et al. Anaplasma marginale type IV secretion system proteins VirB2, VirB7, VirB11, and VirD4 are immunogenic components of a protective bacterial membrane vaccine. Infect Immun 2010;78:1314-25.

104. Cupp EW. Biology of ticks. Vet Clin North Am Small Anim Pract 1991;21:1-26.

105. Lockwood Svetlana, Daniel E Voth, Kelly A Brayton, Paul A Beare, Wendy C Brown. Identification of Anaplasma marginale type IV secretion system effector proteins. Plos One 2011;6:e2772.

106. Nicholson Graham M, Andis Graudins, Harry I Wilson, Michelle Little, Kevin W Broady. Arachnid toxinology in Australia: from clinical toxicology to potential applications. Toxicon 2006;1:872-98.

107. Ristow Laura C, Halli E Miller, Lavinia J Padmore, Rekha Chettri, Nita Salzman, Melissa J Caimano, et al. The $\beta_{3}$-integrin ligand of Borreliaburgdorferi is critical for infection of mice but not ticks. Mol Microbiol 2012;85:1105-18.

108. Ouyang Zhiming, Manish Kumar, Toru Kariu, Shayma Haq, Martin Goldberg, Utpal Pal, et al. BosR (BB0647) governs virulence expression in Borrelia burgdorferi. Mol Microbiol 2009;74:1331-43.

109. KreilM TR, MEibl. Viral infection of macrophages profoundly alters requirements for induction of nitric oxide synthesis. Virology 1995;212:174-8.

110. AmanoK, M Fujita, $T$ Suto. Chemical properties of lipopolysaccharides from spotted fever group rickettsiae and their common antigenicity with lipopolysaccharides from proteus species. Infect Immunol 1993;61:4350-5.

111. Arulkanthan A, Brown WC, McGuire TC, Knowles DP. Biased immunoglobulin G1 isotype responses induced in cattle with DNA expressing msp1a of Anaplasma marginale. Infect Immun 1999;67:3481-7.

112. Fernandes Everton KK, Vania REP Bittencourt, Donald W Roberts. Perspectives on the potential of entomopathogenic fungi in biological control of ticks. Exp Parasitol 2012;13:300-5.

113. Elston Dirk M. Prevention of arthropod-related disease. J Am Acad Dermtol 2004;51:947-54.

114. Fouche Gerda, Olubukola T Adenubi, Tlabo Leboho, Lyndy J McGaw, Vinny Naidoo, Kevin W Wellington, et al. Acaricidal activity of the aqueous and hydroethanolic extracts of 15 South African plants against Rhipicephalus turanicus and their toxicity on human liver and kidneycells. Onderstepoort J Vet Res 2019;86:1665.

115. Stafford KC. 3rd pesticide use by licensed applicators for the control of Ixodes scapularis (Acari: Ixodidae) in connecticut. J Med Entomol 1997;34:552-8. 
116. Lu YC, WZ Liang, CC Kuo, LJ Hao, CT Chou, CR Jan, et al. Action of the insecticide cyfluthrin on $\mathrm{Ca}^{2+}$ signal transduction and cytotoxicity in human osteosarcoma cells. Hum Exp Toxicol 2020;39:1268-76

117. Qirong Lu, Yaqi Sun, Irma Ares Arturo Anadon, Marta Martinez, Maria Rosa Martinez Larranaga. Deltamethrin toxicity: a review of oxidative stress and metabolism. Environ Res 2019;170:260-81.

118. Wenbing Zhang, Gang Tang, Hongqiang Dong, Qianqian Geng, Junfan Niu, Jingyue Tang, et al. Targeted release mechanism of $\lambda$-cyhalothrinnanocapsules using dopamineconjugated silica as carrier materials Colloids Surf B; 2019;178:153-62.

119. Kumar RB, MX Suresh. Neurotox: a unique database for animal neurotoxins. Int J Pharm Pharm Sci 2015;7:351-4.

120. Asawale KY, MC Mehta, PS Uike. Drug utilization analysis of antisnake venom at a tertiary care centre in central Maharasthtra: a 3y retrospective study. Asian J Pharm Clin Res 2018;11:134-7.

121. Preet P. Peptides: a new therapeutic approach. Int J Curr Pharm Res 2018;10:29-34 